\title{
Review
}

Complications

Diabetes Metab J 2021;45:27-42

https://doi.org/10.4093/dmj.2020.0216

pISSN 2233-6079 · eISSN 2233-6087

DIABET\&S \& METABOLISM JOURNAL

\section{Lost in Translation? Measuring Diabetic Neuropathy in Humans and Animals}

\author{
Heung Yong Jin ${ }^{1}$, Seong-Su Moon ${ }^{2,3}$, Nigel A. Calcutt ${ }^{4}$ \\ ${ }^{1}$ Division of Endocrinology and Metabolism, Department of Internal Medicine, Jeonbuk National University Medical School, Research Institute of Clinical \\ Medicine of Jeonbuk National University-Biomedical Research Institute of Jeonbuk National University Hospital, Jeonju, \\ ${ }^{2}$ Department of Internal Medicine, Dongguk University College of Medicine, Gyeongju, \\ ${ }^{3}$ Division of Endocrinology, Department of Internal Medicine, Nazareth General Hospital, Daegu, Korea, \\ ${ }^{4}$ Department of Pathology, University of California San Diego, La Jolla, CA, USA
}

The worldwide diabetes epidemic is estimated to currently afflict almost 500 million persons. Long-term diabetes damages multiple organ systems with the blood vessels, eyes, kidneys and nervous systems being particularly vulnerable. These complications of diabetes reduce lifespan, impede quality of life and impose a huge social and economic burden on both the individual and society. Peripheral neuropathy is a debilitating complication that will impact over half of all persons with diabetes. There is no treatment for diabetic neuropathy and a disturbingly long history of therapeutic approaches showing promise in preclinical studies but failing to translate to the clinic. These failures have prompted re-examination of both the animal models and clinical trial design. This review focuses on the functional and structural parameters used as indices of peripheral neuropathy in preclinical and clinical studies and the extent to which they share a common pathogenesis and presentation. Nerve conduction studies in large myelinated fibers have long been the mainstay of preclinical efficacy screening programs and clinical trials, supplemented by quantitative sensory tests. However, a more refined approach is emerging that incorporates measures of small fiber density in the skin and cornea alongside these traditional assays at both preclinical and clinical phases.

Keywords: Diabetic neuropathies; Electrophysiology; Microscopy, confocal; Models, animal; Neuralgia; Peripheral nervous system

\section{DIABETIC NEUROPATHY}

The International Diabetes Federation reported that in 2019 there were an estimated 463 million adults worldwide living with diabetes, a number that projected to rise to 700 million by 2045 [1]. Of these, over half are likely to develop damage to the somatic and/or autonomic peripheral nervous system (PNS) [2]. It is also becoming increasingly appreciated that diabetes damages both the spinal cord (myelopathy) and brain (encephalopathy) such that diabetes is recognized as a prominent risk factor for developing cognitive dysfunction and Alzheimer's disease [3]. There is no Food and Drug Administration (FDA)-approved disease modifying treatment for preventing or slowing progression of diabetic neuropathy other than the recommendation to maintain glycemic control [4] with management of symptomatic consequences such as pain [5]. Maintaining consistent normoglycemia is a challenge for most diabetic patients and while this approach may slow onset and progression of neuropathy in type 1 diabetes mellitus (T1DM) [4] it is increasingly viewed as ineffective for treating neuropathy in type 2 diabetes mellitus (T2DM) [6], which represents the vast majority of diabetic patients. There is thus an urgent need for effective therapies that prevent or reverse diabetic neuropathy. Development of such treatments has been pursued for over 50 years but has been impeded by the complex mechanisms that cause neuropathy and difficulties in translat-

\footnotetext{
Corresponding author: Seong-Su Moon (D) https://orcid.org/0000-0001-8881-3927 Department of Internal Medicine, Dongguk University College of Medicine, 87 Dongdae-ro, Gyeongju 38067, Korea

E-mail: drmoonss@hanmail.net

Received: Aug. 27, 2020; Accepted: Oct. 6, 2020
}

This is an Open Access article distributed under the terms of the Creative Commons Attribution Non-Commercial License (https://creativecommons.org/licenses/by-nc/4.0/) which permits unrestricted non-commercial use, distribution, and reproduction in any medium, provided the original work is properly cited. 
ing plausible therapies from animal models to humans $[7,8]$. Recent advances in unraveling pathogenic mechanisms $[9,10]$ and enhancing clinical trial design [11] have revitalized the potential for agents developed in preclinical studies to translate into novel therapeutics and also highlighted the need for improved and concordant outcome measures in preclinical and clinical research.

\section{CLINICAL ASSESSMENT OF DIABETIC NEUROPATHY}

Diabetic neuropathy most commonly presents as a distal symmetrical polyneuropathy with degeneration of both sensory and motor fibers of the PNS. People with diabetes, pre-diabetes or metabolic syndrome may first become aware of the onset of peripheral neuropathy via indicators of sensory dysfunction such as paresthesias and pain. Neuropathy progresses to sensory loss, foot ulceration and amputation and contributes to comorbidities such as fall-related injuries [12]. Recent American Diabetes Association recommendations suggest yearly screening using temperature and/or pinprick sensation for small fibers, a $128 \mathrm{~Hz}$ tuning fork for vibration perception by large fibers and the $10 \mathrm{~g}$ monofilament for risk of ulceration [13]. Such tests detect both loss and gain of function. Beyond such basic screening tests, nerve conduction studies (NCSs) are commonly used to measure large motor and sensory fiber function and draw broader inferences about progression of neuropathy and neuropathology [14]. Impact on diabetes-induced nerve conduction velocity (NCV) slowing remains the current gold standard for determining drug efficacy in clinical trials $[4,11]$. Quantitative sensory testing (QST) devices that measure temperature and vibration perception were developed for use in clinical trials along with questionnaires to quantify pain and quality of life [12] and there are a number of clinical scoring systems that incorporate these tests, each weighted in a different manner [15]. There is no diagnostic requirement for demonstration of nerve pathology and use of sural nerve biopsy, which was used historically to identify pathology in the nerve trunk and as an outcome measure in clinical trials [16], is not well tolerated. However, there is a growing appreciation that quantification of small fiber pathology by skin biopsy [17] and/or corneal confocal microscopy (CCM) [18] also provides sensitive measures of neuropathy and response to therapeutic intervention [18-23].

\section{Electrophysiology}

\section{Nerve conduction studies}

NCSs allow measurement of myelinated sensory and motor nerve function by transcutaneous stimulation of nerves of the arms and legs with recording of evoked sensory nerve action potentials (SNAPs) and compound action potentials in associated muscles (CMAP) via surface electrodes [24]. Comparing action potential amplitude and velocity to local normative ranges corrected for age, sex and height allows inferences to be drawn about pathophysiological conditions such as demyelination and axon loss [25]. NCS are frequently supplemented by electromyography (EMG), which requires use of needle electrodes inserted into the muscle but provides additional information to assist diagnosis. It should be noted that many electrophysiological studies in rodents use EMG to calculate NCV (see below).

Both reduced SNAP and slowing of motor and sensory nerve conduction velocities (MNCV and SNCV) are detected in patients with diabetic neuropathy, implicating both axonal loss and demyelination as underlying pathologies [25]. NCS can be used in diagnosis, staging and monitoring of progression of diabetic peripheral neuropathy and may also allow prediction of associated comorbidities such as foot ulceration and even mortality [26]. Prominent use of NCS has emerged from FDA guidance indicating that prevention, reversal or attenuation of NCV slowing serve as the primary indicator of efficacy in clinical trials of novel therapeutic agents for diabetic neuropathy. NCV slowing historically exhibited a modest rate of progression ( $<2 \%$ per year) in cohorts of diabetic subjects [27] and in recent years this rate may have further slowed due to general improvements in glycemic control and increased use of drugs such as ACE inhibitors and lipid-lowering agents for other complications of diabetes but which also impact neuropathy $[28,29]$. Consequently, use of NCV as a primary outcome measure imposes clinical trial designs requiring large cohorts of subjects with mild-moderate neuropathy who are followed over long periods of time by skilled reference labs in order to detect treatment efficacy $[11,30]$. This makes clinical trials extremely expensive to undertake. Moreover, NCS assess only large fiber function while there is an emerging appreciation that small fibers are damaged early in the course of diabetes and mediate the symptoms of most concern to patients [31]. Thus, while currently considered the gold standard for diagnosis of diabetic peripheral neuropathy, NCS are usually only recommended in general practice to exclude other neuropath- 
ic diseases when a diabetic patient has an atypical pattern of symptoms or signs and there are growing calls for measures of small fiber neuropathy to have equal status as outcome measures in clinical trials [19].

\section{Rate dependent depression}

A simple modification to the EMG procedures described above can be used to provide additional information on the function of spinal inhibitory systems. Adjusting the nerve stimulator to provide trains of stimuli at the voltage that gives maximal $\mathrm{H}$ wave amplitude allows measurement of rate dependent depression (RDD) of the $\mathrm{H}$ wave, in which $\mathrm{H}$ wave amplitude declines over consecutive stimuli [32]. Patients with spinal injury exhibit loss of this RDD [33], as do animals with loss of spinal GABAergic systems due to ischemic trauma [34]. Reports that diabetic rodents also show an absence of RDD that parallels indices of painful neuropathy (see below) have led to the hypothesis that RDD acts as a biomarker of spinal inhibitory function and can identify pain states arising from spinal disinhibition [35,36]. In support of this, a recent clinical study identified impaired RDD in a sub-population of T1DM subjects with painful neuropathy [37], offering the possibility of using this test to stratify patient entry to clinical trials of anti-pain agents with known sites of action and for personalized, lesion-specific, treatment strategies. RDD may serve as a counterpoint to microneurography, which has been used as a means of identifying subjects with potentially peripherally driven pain (see below).

\section{Microneurography}

Microneurography is used to measure electrical activity of peripheral sensory afferents via an intraneural microelectrode inserted through the skin into a peripheral nerve in the awake subject [38]. Baseline spontaneous activity may be recorded, while cutaneously-applied stimuli are used to activate individual fibers, thereby defining their sensory modality sub-type. Abnormal spontaneous action potentials in C-nociceptors have been associated with spontaneous pain [39] and increased stimulus evoked firing activity with nociceptor sensitization [40]. At present, only a limited number of studies have employed microneurography in diabetic subjects because of the invasive and time consuming protocols required by skilled investigators. It has been suggested that analgesic efficacy in human clinical trials could be accessed by microneurography [41] and the technique has been used to identify subjects with hyperactive peripheral nerves and pain for entry into a clinical trials of a therapy that specifically targeted peripheral nerve activity in order to increase potential for success [38,42]. Future studies that use both microneurography and RDD assessment (see above) could offer a powerful approach to stratifying subjects to targeted therapies.

\section{Sensory perception and pain \\ Quantitative sensory testing}

QST is used to detect small and large fiber dysfunction in early stage diabetic peripheral neuropathy [43]. QST involves measuring thermal threshold for subjective cold (A- $\delta$ fibers) and warm (c fibers) sensations, and may detect positive (hyperalgesia) and negative (hypoalgesia) aspects of small fiber neuropathy that NCSs cannot measure. Vibration perception by large myelinated sensory fibers, assessed using a biothesiometer, is also a component of QST and a useful predictor for foot ulceration. These standardized measures of thermal and vibration perception thresholds have been described as sufficiently reproducible to be used as efficacy endpoints in clinical trials of potential therapeutics for diabetic neuropathy [44-46], although concerns have been raised regarding use as the sole primary endpoint [47] and diagnostic efficiency compared to other tests [48]. In a recent clinical trial of C-peptide to treat neuropathy in T1DM subjects, significant efficacy was achieved using vibration perception as the indicator whereas no significant effect was noted on nerve conduction, in part due to an unanticipated placebo effect [49]. The perceived failure of this clinical trial illustrates the dominant reliance on electrophysiology in the current clinical trials climate.

\section{Scoring of subjective symptoms}

In the diagnosis of diabetic neuropathy, the subjective assessment and quantification of neuropathic symptoms and pain can be achieved by use of one or more questionnaire-based scoring systems. These questionnaires are reproducible and include standardized and validated scores for both the severity of symptoms and the degree of neuropathic deficits. Examples in current use that focus on pain include the McGill Pain Questionnaire [50], the Brief Pain Inventory [51], and the Neuropathic Pain Symptom Inventory [52]. The Michigan Neuropathy Screening Instrument [53] is also a useful tool in screening for diabetic neuropathy. Each system has its own components and weighting. For example, the Neuropathy Symptom Score includes burning, numbness, or tingling, fatigue, cramping, 
aching, or nocturnal exacerbation while the Neuropathy Disability Score and Neuropathy Impairment Score are calculated using ankle reflex, pinprick sensation, temperature sensation, and vibration. Based on the Toronto Clinical Neuropathy Score [54], diabetic patients can be categorized as having mild, moderate or severe neuropathy by summation of symptom scores. Repeated deployment of a battery of these questionnaires allows iterative monitoring of neuropathic symptoms and therapeutic responses throughout clinical trials. Despite reflecting the patients perspective they tend to serve as adjuncts to physiological assays of nerve function due to perceived subjectivity and variability.

\section{Nerve pathology \\ Nerve biopsy}

Nerve biopsy is not required for diagnosis of diabetic neuropathy given its relatively invasive nature compared to assessment of symptoms and electrophysiology as described above. Early autopsy studies provided insight into the structural damage caused by chronic diabetes, such as Wallerian degeneration and segmental demyelination but tended to emphasize late stage pathology. Biopsy studies conducted as part of research programs have allowed documentation of earlier stages of diabetes-induced neuropathology, such as microangiopathy [55] and early reactive, degenerative and proliferative changes in Schwann cells [56]. Such studies helped guide formulation of potential pathogenic mechanisms, were used to investigate potential associations between pain and nerve degeneration/regeneration profile [57] and have highlighted diabetic cats as the preclinical model that most closely reflects human diabetic neuropathology [58]. Nerve biopsies have also been used in clinical trials to assess efficacy of potential therapeutic agents to promote axon regeneration $[59,60]$ and remyelination [16]. However, expense, assay variability and a focus on large myelinated fibers, as well as the invasive and non-iterative nature of the procedure, has limited use of nerve biopsies in clinical trials and there has been a move towards less invasive or noninvasive approaches to visualizing small fiber pathology such as skin biopsy and CCM to complement large fiber NCV slowing in clinical trials [19].

\section{Skin biopsy}

It is widely held that small sensory nerves are the first to show impairment in diabetes [61] and patients are certainly likely to have a greater awareness of sensory, rather than motor, dys- function. Other then the sensory perception tests described above, visualization of small unmyelinated sensory fibers in the epidermis via a skin biopsy offers the opportunity to quantify distal nerve endings (intra-epidermal nerve fibers [IENFs]) as an index of small fiber pathology $[17,62,63]$. The standardized procedure requires a 3-mm punch skin biopsy at the distal leg and quantification of the linear density of nerves crossing the dermal:epidermal interface in at least three $50 \mu \mathrm{m}$ thick sections per biopsy. Mean dendritic length, a measure of all nerve length in the epidermis can also be quantified to assess early remodeling of IENF prior to retraction/degeneration or collateral sprouting in response to therapy that is independent of regrowth from the dermis $[63,64]$. Sensory nerves are visualized using anti-protein gene product 9.5 antibodies [65] and bright-field or immunofluorescence microscopy, with the caveat that Langerhans cells, dendritic cells of the epidermis, are also stained (Fig. 1) so that their processes must be differentiated from IENF [66]. Other than nerve density, discrete axonal swellings within IENF can also be quantified [67] and have been suggested to be linked to early pathophysiological processes of axonopathy [68-70]. Nerve regeneration capacity can also be assessed by combining local denervation by topical capsaicin with subsequent skin biopsy and IENF quantification [71]. Because skin biopsies capture the epidermis, the papillary dermis and portions of the reticular dermis, dermal myelinated nerve fibers innervating dermal mechanoreceptors and autonomic nerve fibers innervating sweat glands may also be quantified (Fig. 1) [72].

Diabetes causes progressive loss of IENF to almost complete ablation. There is early loss of IENF in subjects with impaired glucose tolerance and diabetes that precedes significant large fiber NCV slowing [73] so that it is considered to be an objective means to detect early small nerve damage in diabetes. Skin biopsies are not widely used in clinical diagnosis of diabetic neuropathy because they are invasive, slow to provide data and costly compared to other tests $[17,62,70]$. However, the ability to repeatedly sample adjacent biopsy sites over time means they are becoming an important component of clinical trials, particularly for agents that target mechanisms of nerve regeneration in small fibers. IENF regeneration is inherently impaired by diabetes [71] and only a few studies have reported improvement of epidermal innervation after intervention. In T2DM subjects, 10 weeks of increased aerobic exercise increased epidermal nerve fiber branching [74] while longer periods of lifestyle modification significantly increased IENF density in subjects 

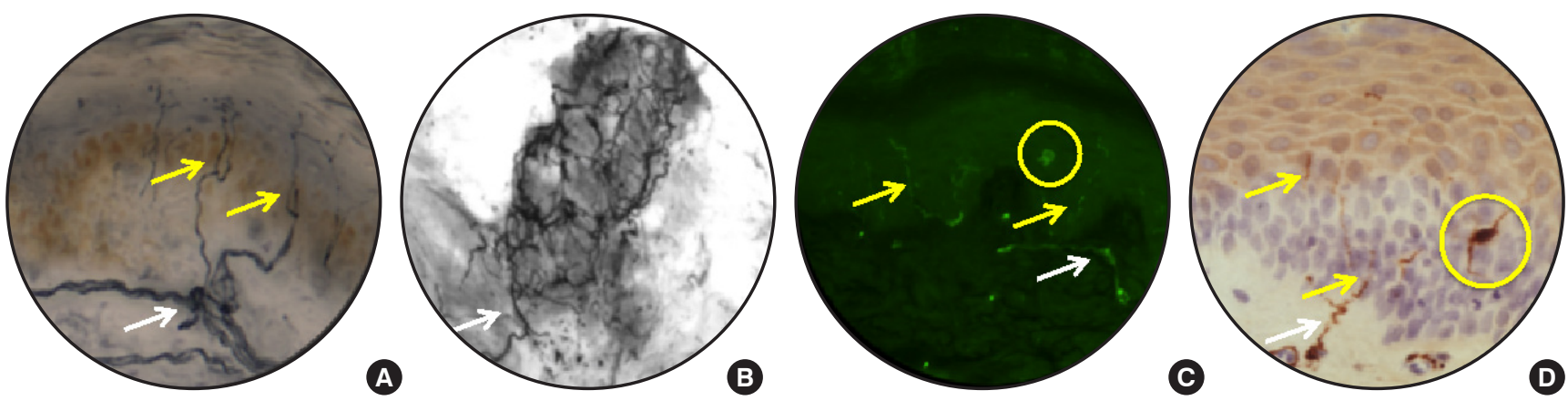

Fig. 1. Dermal and epidermal nerves identified using anti-protein gene product 9.5 antibody in human (A, B), rat (C), and mouse (D) skin. Tissue was prepared as either $50 \mu \mathrm{m}$ frozen sections (A, B) or $6 \mu \mathrm{m}$ sections cut from paraffin blocks (C, D) with visualization using birghtfield (A, B, D) or immunofluorescence (C) microscopy. (A ,B) Image-Pro Plus software (Media Cybernetics Inc.) was used to generate a composite of serial images, alllowing tracking of nerves across multiple planes of section in the dermis and epidermis (A) and around a dermal sweat gland (B). White arrows indicate dermal nerves and yellow arrows indicate epidermal nerves (IENF). Yellow circles surround Langerhans cells and their processes. Images courtesy of Katie Frizzi and Lucie Guernsey.

with impaired glucose tolerance or T2DM [75,76]. Simultaneous pancreas and kidney transplant that effectively cured patients with severe T1DM also increased mean dendritic length of IENF, although not IENF quantified by the standard clinical method [64]. Assessment of IENF in skin biopsies provides a useful measure of small fiber pathology to accompany QST and large fiber NCV studies and should perhaps serve as the primary outcome measure in clinical trials of agents that target small fiber regeneration. As IENF loss also occurs in rodent models of diabetes (see below), the assay may also serve as a suitable bridge for translating experimental therapies.

\section{Corneal confocal microscopy}

CCM is an emerging tool being developed for measuring impact of systemic diseases such as diabetes on small sensory fibers [77]. It visualizes in real-time the sub-basal nerve plexus of the cornea without need for contrast agents (Fig. 2) and is a non-invasive and relatively inexpensive procedure that allows iterative measurements of the same nerves. Automated image analysis algorithms have been developed to remove inter-observer variability and accelerate data delivery [78,79]. These features support suitability for tracking progression of neuropathy and also recovery following therapeutic intervention [80]. Loss of corneal nerve density correlates with severity of neuropathy and other measures of small fiber neuropathy such as IENF loss [22] and CCM can detect early small-fiber axonal damage in diabetic neuropathy $[81,82]$. The sensitivity and specificity for the diagnosis of diabetic neuropathy have been established [83] and corneal nerve loss predicts incident neuropathy in those with poorer glycemic control and lower high density lipoprotein [84]. At present there are few studies showing recovery of corneal nerve loss in diabetic subjects treated with therapeutic agents, other than one showing increased corneal nerve density following 1 year of improved glycemic control [85]. The most compelling data comes from a longitudinal study of formerly diabetic patients who underwent simultaneous pancreas and kidney transplantation that effectively cured diabetes. Significant improvement in corneal nerve parameters preceded detectable efficacy against other indices of neuropathy such as neuropathy symptom profile score, large fiber conduction slowing and reduced IENF density [64]. Despite the promising advances, there is ongoing debate regarding how well corneal nerves will serve as surrogates or biomarkers for other sensory nerves during systemic disease, given their relatively short length and unique local environment. Nevertheless, use of CCM to monitor small fiber neuropathy is an exciting development that, like IENF loss, can also be used preclinical models of diabetes.

\section{MODELS OF DIABETIC NEUROPATHY}

Many of the assays used to identify neuropathy in diabetic patients are also amenable to use in preclinical models [86] and are used to identify agents with most translational potential, provided that the disorders share the same pathogenic mechanisms. 

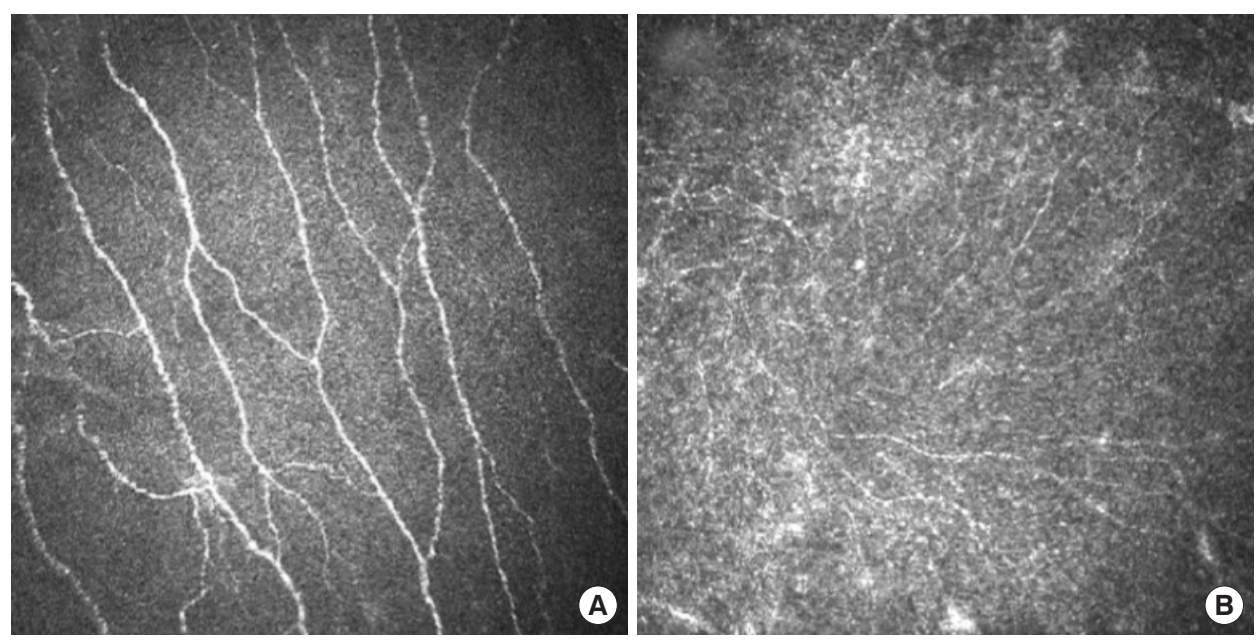

Fig. 2. Images of the corneal sub-basal nerve plexus in a human (A) and a BALB/c mouse (B) taken using a corneal confocal microscope (HRT 3 with Rostock Corneal Module; Heidelberg Engineering). The relatively broad and well-defined nerves of the human allow automated image analysis of total nerve length, nerve density and branch points whereas the finer mouse nerves are not accurately detected by current imaging systems and require image enhancement and tracing by hand. Images courtesy of Katie Frizzi and Morgan Cundiff.

\section{Cell culture}

Early in vitro studies using immortalized cells lines have evolved so that Schwann cells and peripheral sensory neurons derived from adult rodents are now widely used to investigate cellular mechanisms linked with diabetic neuropathy. Such studies have identified a number of plausible pathogenic cascades that warrant further exploration in more complex systems $[87,88]$. Advantages of using such systems include the ability to design relatively fast studies (over days-weeks, not months-years), control of environmental conditions and drug delivery, the ability to track real time intracellular events within a specific cell type and minimal ethical concerns. There is particular value in using sensory neurons derived from adult rodents to identify agents that promote neurite outgrowth and thus have potential for encouraging axonal regeneration following traumatic injury or protecting against neuropathy [89]. However, there are also caveats regarding the pertinence of excised tissues maintained in an artificial (and probably incomplete) environment, particularly as transection of axons during dorsal root ganglion (DRG) removal prompts an injury and regeneration phenotype while Schwann cells revert to a nonmyelinating status. It is also worth noting that most culture media used to sustain neurons already contains glucose concentrations of $20 \mathrm{mM}$ or more, this being in marked excess of those considered hyperglycemic in vivo, making experimental design and interpretation difficult. Sophisticated cell culture systems employ cells derived from adult normal and diabetic animals that are excised and maintained under in vitro conditions that reflect the source glycemic and insulin environment [90] and co-culture Schwann cells and neurons to promote myelination [91,92].

\section{Animals}

Diabetic cats develop pathology that most closely reflects advanced human diabetic neuropathy, with overt demyelination and axonal degeneration in nerve trunks [58]. However, rats and mice are most widely studied as models of diabetic neuropathy and are responsible for providing the vast majority of data that supports current hypotheses of the pathogenesis of diabetic neuropathy and translation of potential therapies. Both rats and mice can model pre-diabetes, T1DM or T2DM using genetic, chemical or dietary insults and while there are model-specific variations in the presentation and progression of neuropathy, there is a broadly consistent phenotype that models the human condition of both loss and gain of function [93].

Rodent models of T1DM or T2DM reliably show many functional disorders of the early human condition, including large fiber MNCV and SNCV slowing and allodynia/hyperalgesia to sensory stimuli that in some cases, such as heat hyperalgesia in diabetic rats, progresses to sensory loss [86]. They also go on to replicate some features of early structural pathol- 
ogy in humans such as reduced density of epidermal [94] and corneal [95] small sensory nerve fibers, along with myelin thinning and reduced caliber of large myelinated sensory and motor axons and their perikarya [96-100]. Descriptions of encephalopathy with accompanying cognitive impairment [101, 102] suggest viability as models of the Alzheimer's Disease-like condition increasingly reported in long-term diabetes [103].

Aside from inescapable features of rodent biology such as short life span, physically short nerves and tolerance of levels of hyperglycemia ( 25 to $60 \mathrm{mM}$ ) that are fatal in humans, there are also a number of other caveats to be borne in mind when using rodent models of diabetic neuropathy or interpreting data from such studies. One major weakness of rodent models is their poor replication of the late structural pathology of human diabetic neuropathy. Most intriguingly, there is little overt Schwann cell pathology or demyelination, despite this being a prominent feature of the human condition. After half a century of neuropathologists failing to find reliable evidence of overt myelin disruption in rodent models of diabetes, other than mild myelin thinning detected in nerve cross sections and occasional segmental demyelination and reduced internodal distance measured in teased fibers [96,104-109], there is a current tendency to identify dramatic myelin damage within weeks of onset of diabetes in the same models. Whether this reflects evolution of the models to a more desirable phenotype or enhanced/diminished interpretative skills in the research community will presumably be resolved over time. Features indicative of demyelination and subsequent remyelination such as thin myelin with supernumerary Schwann cells can be reproduced by superimposing hypertension onto T1DM rats [110]. Hypertension is a major risk factor for neuropathy in diabetes [111] and, as many rodent models of diabetic neuropathy are normotensive or mildly hypotensive [110], a lack of cumulative risk factors may restrict the rapid evolution of a humanlike neuropathology phenotype.

Concerns have been raised that the pancreatic beta cell toxin streptozotocin (STZ), which is widely used to produce rodent models of T1DM, causes direct neurotoxicity. These concerns arose initially when STZ-injected animals that did not develop hyperglycemia showed indices of neuropathy [112]. Subsequent studies associated mechanical hyperalgesia with STZinduced insulin depletion that, while not sufficient to induce overt hyperglycemia, presumably impacted insulin signaling in nerve $[113,114]$. Thermal hyperalgesia was also linked to increased expression of the transient receptor potential vanilloid receptor 1 (TRPV1) channel via oxidative stress [115]. More recently, STZ has been reported to directly activate transient receptor potential ankyrin subtype 1 (TRPA1) receptors on adult-derived sensory neurons in vitro and produce an acute, transient allodynia following intraplantar injection in mice that resolved within 24 hours-before onset of diabetes [116]. However, in vivo STZ is largely removed from the blood within 15 minutes and cleared in the urine within 2 to 6 hours [117]. Initial ( 2 to 3 days) hyperinsulinemia and hypoglycemia due to pancreatic beta cell necrosis is followed by hypoinsulinemia and hyperglycemia. Most indices of neuropathy emerge after 2 to 8 weeks of hyperglycemia and appear unlikely to reflect direct neurotoxicity of STZ. Nevertheless, such concerns highlight the need to establish the provenance of newly-identified disorders in STZ-diabetic rodents which can be achieved using 3-O-methyl glucose $[37,118]$, by reversal of established disorders with insulin therapy to continuously normalize blood glucose levels [37] and parallel use of models of diabetes arising from genetic or dietary insults [119].

The widely used rodent models of diabetes are perhaps best viewed as modeling early functional and structural indices of neuropathy. This allows molecular and biochemical changes in nerve to be interpreted as potential pathogenic mechanisms that lead to degenerative neuropathy. However, it should be remembered that the mild neuropathy of these models prevents guarantees that any therapies emerging from their use will prevent or reverse the more advanced stages of clinical diabetic neuropathy.

\section{Assays}

\section{Electrophysiology}

Preclinical studies of NCV frequently utilize shifts in M and $\mathrm{H}$ wave latency of the EMG following stimulation at different sites to calculate velocity [86]. MNCV/SNCV slowing occurs within weeks of onset of diabetes in almost all animal models of diabetes and is commonly used in preclinical drug development as a primary measure of therapeutic efficacy, in part because this has been the FDA-defined primary end point in most clinical trials (see above). However, it must be cautioned that having the same dysfunction as humans does not automatically indicate that disorders measured in both species arise by the same mechanism. For example, NCV slowing in short term diabetic rodents is initially of metabolic origin and not associated with any detectable structural pathology to axons or myelin [120], whereas axonal degeneration and demyelination 
are prominent in humans [55] and likely to contribute to NCV slowing in subjects enrolled in clinical trials [11]. This discord may explain why the impressive efficacy of drugs that interrupt glucose metabolism against NCV slowing in short term diabetic rodents [121] has not been replicated in clinical trials, where only modest effects have been reported $[30,122]$.

CMAP is relatively stable in humans due to the large muscle groups being sampled, thereby allowing inferences about axonal and muscle pathology. In contrast, CMAP is much less stable in rodents, so that use of this aspect of clinical electrodiagnostic testing to assess between-animal and between group pathology is less reliable. Nevertheless, measuring CMAP amplitude during bursts of stimulation to a restrained limb can replicate the clinical observation that maximal $\mathrm{M}$ wave amplitude remains constant while maximal $\mathrm{H}$ wave amplitude in the same EMG declines in a frequency-dependent manner [32]. $\mathrm{RDD}$ in rodents is attributed to release of GABA as the initial stimulus traverses the spinal cord with inhibition of subsequent components of the stimulus train via actions on spinal $\mathrm{GABA}_{\mathrm{A}}$ receptors [35]. RDD thus serves as an electrical biomarker of spinal GABAergic inhibitory functions. RDD is impaired in diabetic rodents due to disruption of the $\mathrm{GABA}_{\mathrm{A}}$ receptor inhibitory functions secondary to decreased expression of the potassium and chloride transporting potassium-chloride cotransporter 2 (KCC2) pump [35] located in the postsynaptic membrane. As both RDD and indices of neuropathic pain covary in diabetic rodents and both respond in a similar manner to assorted spinal pharmacological manipulations it has been proposed that loss of RDD may serve as a biomarker for pain in which loss of spinal GABAergic inhibition plays a role [36]. Potential clinical utility of this phenomenon is suggested by a recent clinical study indicating that a sub-group of T1DM patients with pain show loss of RDD [37].

\section{Sensory perception and pain}

Behavioral responses to sensory stimuli are widely used as surrogates of presumed pain perception in diabetic rodents, with all the attendant caveats that apply to use of such evoked response tests when used to define other models of neuropathic pain $[123,124]$. The physiology of diabetes brings additional concerns that muscle wasting and protein glycation in skin can also modify behavioral responses. Commonly reported indices of painful neuropathy in multiple rodent models include allodynia to von Frey filaments, hyperalgesia in the paw pressure (Randall-Siletto), hot plate and Hargreaves heat tests (with progression to hypoalgesia in some longitudinal studies), allodynia/hyperalgesia in the acetone and cold plate tests and allodynia/hyperalgesia in the paw formalin test [125]. Not all sensory tests are universally disrupted in all models of diabetes. Anomalies include hyperalgesia in the paw formalin test of STZ-diabetic rats [126] but hypoalgesia in STZ-diabetic mice [127] and the persistence of heat hyperalgesia in some studies but progression to hypoalgesia in others. The latter may reflect relative severity of STZ-induced insulin depletion and unreported use of trace insulin to protect against extreme cachexia, as trace insulin therapy that does not impact hyperglycemia prevented the progression from heat hyperalgesia to hypoalgesia [128]. Increased sensitivity of diabetic rodents to von Frey filaments appears to be particularly reproducible between species, strains, models and investigators and is widely used to evaluate potential analgesics despite brush-evoked tactile allodynia not being a universal representation of painful neuropathy in diabetic subjects [129].

Diabetic rodents do not display behaviors associated with extreme or spontaneous ongoing pain such as autotomy, guarding behavior, vocalization upon touching the body or ultrasonic vocalizations [130], and well-maintained diabetic rodents are indistinguishable from controls in open-field behavior. Evidence for spontaneous pain in diabetic rodents has been largely restricted to electrophysiological studies suggesting spontaneous or enhanced evoked activity in peripheral nerve $[131,132]$ and/or spinal cord [133-136] and bears the caveat that stimulus-evoked neurotransmitter release in the cord of diabetic rats is reduced, not increased $[137,138]$. Conditioned place preference (CPP) tests have been deployed to assess use of anti-pain drugs and employ preference as a surrogate for ongoing pain. Initial studies in STZ-diabetic rats disassociated discernable effects of a TRPA1 channel antagonist on mechanical hyperalgesia from lack of effect in a CPP assay and therefore were unable to support the implication of ongoing pain in the model [139]. More recent studies demonstrated CPP using soluble epoxide hydrolase inhibitors $[140,141]$ or pregabalin [142] that also alleviated abnormal responses to evoked pain tests. Such findings are likely to support addition of CPP to the battery of tests viable in diabetic rodents for use in drug development programs.

\section{Nerve pathology}

As discussed above, degeneration of nerve fibers in peripheral nerves of diabetic rodents is controversial, with many careful 
morphometric studies suggesting that pathology during the first few months of diabetes is limited to reduced perikaryal and axonal diameter and eventual myelin thinning in the absence of overt demyelination, degeneration, and axonal loss. These features have the potential to contribute a structural component to large fiber conduction slowing in long-term diabetic rodents. Reports of myelin disruption and frank demyelination in short term diabetic rodents have yet to be supported by convincing documentation using electron microscopy. Like humans, small sensory fibers may be visualized in skin biopsies and in situ via CCM (Figs. 1 and 2) and diabetes causes a progressive reduction of small fiber density in both tissues $[95,143]$. The functional consequences may be reflected in paw thermal hypoalgesia and diminished corneal reflexes. However, onset of hypoalgesia precedes detectable loss of epidermal nerves in diabetic mice [144] and early neurochemical disorders such as impaired synthesis, transport and evoked spinal release of sensory neurotransmitters $[137,138,145,146]$ may also contribute to early sensory loss. Whether loss of corneal and epidermal sensory nerves in diabetic rodents shares the same pathogenesis as that seen in humans remains to be established.

\section{CONCLUSIONS AND SPECULATION}

A major value of preclinical models of disease comes from identification and stress testing of potential pathogenic mechanisms and therapeutic approaches. The capacity to translate preclinical discoveries into therapeutic approaches for human disease is largely dependent on the fidelity of the preclinical models to the human condition and use of common assays of therapeutic efficacy. Unfortunately, the translation from preclinical promise to clinical approval for therapies directed at diabetic neuropathy over the last 50 years has been littered with failure, with the blame equally distributed between imperfect drug design, preclinical models and clinical trial design. The historical focus on amelioration of NCV slowing in short term diabetic rodents as the primary readout to predict efficacy against NCV slowing in clinical trials may have contributed to these translational failures, given the largely metabolic dysfunction underlying the rapid and dramatic NCV slowing in rodents and the substantial structural contribution to the slowly evolving NCV slowing in humans [147]. For example, while aldose reductase inhibitors completely protect NCV in diabetic rodents [121], the minor impact reported in the most thorough clinical studies [30] may indeed reflect the best achievable outcome for a metabolic intervention.

The growing appreciation that diverse pathogenic mechanisms deriving from both glucotoxic and non-glucose driven primary lesions may contribute to diabetic neuropathy $[9,10]$ is driving both consideration of polypharmaceutical approaches [148] and also use of more refined preclinical development programs that require progression through a variety of model systems using efficacy readouts with direct clinical equivalents. One such development funnel, designed to identify therapies that promote nerve regeneration and neuroprotection, is shown in Fig. 3. Compounds emerging from synthesis platforms or existing libraries are initially screened for axonal growth and survival properties using adult sensory neuron cultures de-

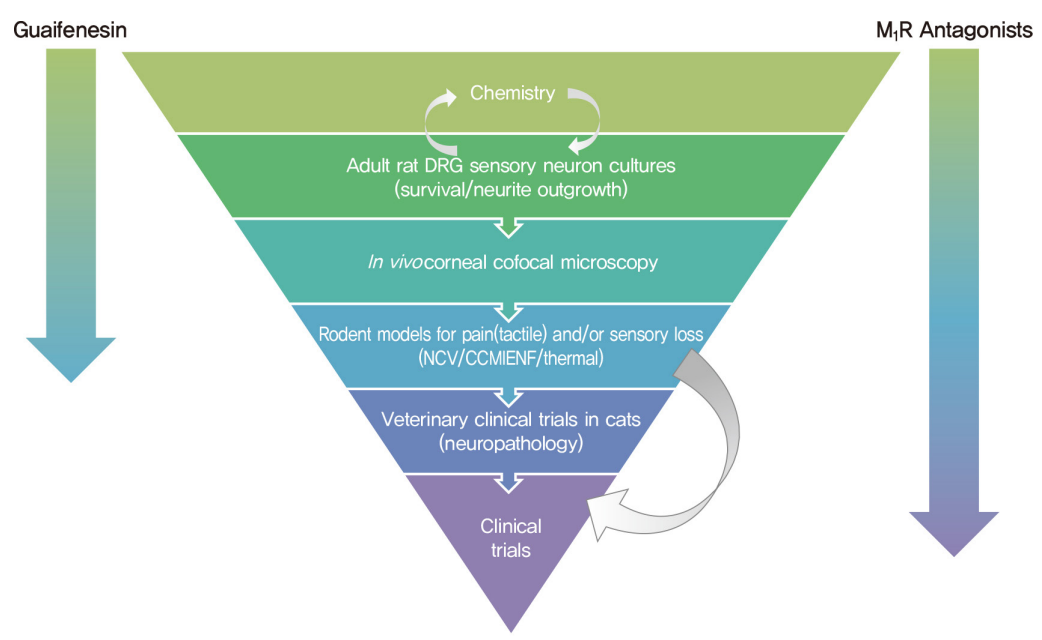

Fig. 3. Therapeutic development funnel designed to identify neuroprotective and regenerative agents for use against diabetic neuropathy. Progression of guaifenesin and $\mathrm{M}_{1}$ receptor $\left(\mathrm{M}_{1} \mathrm{R}\right)$ antagonists through the funnel is indicated by arrows. 
rived from normal and diabetic rodents, with hits being refined by medical chemistry approaches before progressing to assay of sensory nerve growth in the cornea of normal and diabetic rodents after topical delivery. This provides a relatively fast path to first in vivo data. Efficacy supports advancement to systemic delivery studies in diabetic rodents using multiple small and large fiber indices of neuropathy. Veterinary clinical trials in diabetic cats offer an optional late screen for impact on nerve pathology that mirrors the human condition. In one example of this approach, an in vitro screen of 600 compounds using sensory neurons derived from adult rat DRG identified guaifenesin as a potent enhancer of neurite outgrowth while subsequent structural refinements isolated the biological activity to the R-enantiomer [89]. This was unexpected, as guaifenesin is commonly included in cough medicine formulations as an expectorant but had no reported neuron-stimulating properties. Subsequent studies in diabetic mice demonstrated that both the R-enantiomer and racemic guaifenesin attenuated MNCV slowing. In another example, in vitro studies identified neuritogenic properties of non-selective muscarinic antagonists and also both selective and specific antagonists of the $\mathrm{M}_{1}$ receptor $\left(M_{1} R\right)$ sub-type. Varying the in vitro assay by using sensory neurons from $M_{1} R$ knock out or overexpressing mice confirmed the focus on this receptor sub-type, while coupling with assays of calcium signaling and mitochondrial respiration allowed the molecular and cellular consequences to be investigated [149]. Predictive strength of the in vitro system was supported by subsequent studies showing that treatment with a $M_{1} R$ selective antagonist prevented and reversed small fiber dysfunction, along with large fiber conduction slowing, in multiple rodent models of T1DM and T2DM and advancement to phase 2 clinical trials. While this is not the only viable testing funnel, it is hoped that use of multiple preclinical assays that replicate both functional and structural indices of human diabetic neuropathy will reduce the incidence of false positives and identify more robust therapies that translate to clinical use.

\section{CONFLICTS OF INTEREST}

Nigel A. Calcutt is a co-founder and shareholder in Winsantor Inc. The terms of this arrangement have been reviewed and approved by the University of California, San Diego in accordance with its conflict of interest policies.

\section{ORCID}

Heung Yong Jin https://orcid.org/0000-0002-1841-2092

Seong-Su Moon https://orcid.org/0000-0001-8881-3927

\section{FUNDING}

None

\section{ACKNOWLEDGMENTS}

This study was supported by American Diabetes Association (ADA) award 1-17-ICTS-062 (Nigel A. Calcutt).

\section{REFERENCES}

1. International Diabetes Federation. Diabetes Atlas 2019. 9th ed. Brussels: IDF; 2019.

2. Pirart J. Diabetes mellitus and its degenerative complications: a prospective study of 4,400 patients observed between 1947 and 1973. Diabete Metab 1977;3:97-107.

3. Velayudhan L, Poppe M, Archer N, Proitsi P, Brown RG, Lovestone S. Risk of developing dementia in people with diabetes and mild cognitive impairment. Br J Psychiatry 2010;196:3640.

4. Pop-Busui R, Martin C. Neuropathy in the DCCT/EDIC: what was done then and what we would do better now. Int Rev Neurobiol 2016;127:9-25.

5. Alam U, Sloan G, Tesfaye S. Treating pain in diabetic neuropathy: current and developmental drugs. Drugs 2020;80:363-84.

6. Rodriguez-Gutierrez R, Montori VM. Glycemic control for patients with type 2 diabetes mellitus: our evolving faith in the face of evidence. Circ Cardiovasc Qual Outcomes 2016;9:50412.

7. Fernyhough P, Calcutt NA. An introduction to the history and controversies of the pathogenesis of diabetic neuropathy. Int Rev Neurobiol 2016;127:115-20.

8. Calcutt NA, Fernyhough P. An introduction to the history and controversies of animal models of diabetic neuropathy. Int Rev Neurobiol 2016;127:45-52.

9. Yagihashi S. Glucotoxic mechanisms and related therapeutic approaches. Int Rev Neurobiol 2016;127:121-49.

10. Zochodne DW. Sensory neurodegeneration in diabetes: beyond glucotoxicity. Int Rev Neurobiol 2016;127:151-80.

11. Bril V. The perfect clinical trial. Int Rev Neurobiol 2016;127: 
27-41.

12. Vinik AI, Casellini C, Nevoret ML. Alternative quantitative tools in the assessment of diabetic peripheral and autonomic neuropathy. Int Rev Neurobiol 2016;127:235-85.

13. Pop-Busui R, Boulton AJ, Feldman EL, Bril V, Freeman R, Malik RA, et al. Diabetic neuropathy: a position statement by the American Diabetes Association. Diabetes Care 2017;40: 136-54.

14. Dyck PJ, Albers JW, Andersen H, Arezzo JC, Biessels GJ, Bril V, et al. Diabetic polyneuropathies: update on research definition, diagnostic criteria and estimation of severity. Diabetes Metab Res Rev 2011;27:620-8.

15. Zilliox LA, Ruby SK, Singh S, Zhan M, Russell JW. Clinical neuropathy scales in neuropathy associated with impaired glucose tolerance. J Diabetes Complications 2015;29:372-7.

16. Kalichman MW, Chalk CH, Mizisin AP. Classification of teased nerve fibers for multicenter clinical trials. J Peripher Nerv Syst 1999;4:233-44.

17. Lauria G, Hsieh ST, Johansson O, Kennedy WR, Leger JM, Mellgren SI, et al. European Federation of Neurological Societies/Peripheral Nerve Society Guideline on the use of skin biopsy in the diagnosis of small fiber neuropathy. Report of a joint task force of the European Federation of Neurological Societies and the Peripheral Nerve Society. Eur J Neurol 2010; 17:903-12.

18. Petropoulos IN, Ponirakis G, Khan A, Almuhannadi H, Gad H, Malik RA. Diagnosing diabetic neuropathy: something old, something new. Diabetes Metab J 2018;42:255-69.

19. Malik RA. Wherefore art thou, o treatment for diabetic neuropathy? Int Rev Neurobiol 2016;127:287-317.

20. Kennedy WR, Wendelschafer-Crabb G, Johnson T. Quantitation of epidermal nerves in diabetic neuropathy. Neurology 1996;47:1042-8.

21. Malik RA, Tesfaye S, Newrick PG, Walker D, Rajbhandari SM, Siddique I, et al. Sural nerve pathology in diabetic patients with minimal but progressive neuropathy. Diabetologia 2005; 48:578-85.

22. Quattrini C, Tavakoli M, Jeziorska M, Kallinikos P, Tesfaye S, Finnigan J, et al. Surrogate markers of small fiber damage in human diabetic neuropathy. Diabetes 2007;56:2148-54.

23. Tavakoli M, Quattrini C, Abbott C, Kallinikos P, Marshall A, Finnigan J, et al. Corneal confocal microscopy: a novel noninvasive test to diagnose and stratify the severity of human diabetic neuropathy. Diabetes Care 2010;33:1792-7.

24. Tavee J. Nerve conduction studies: basic concepts. Handb Clin
Neurol 2019;160:217-24.

25. Perkins B, Bril V. Electrophysiologic testing in diabetic neuropathy. Handb Clin Neurol 2014;126:235-48.

26. Carrington AL, Shaw JE, Van Schie CH, Abbott CA, Vileikyte L, Boulton AJ. Can motor nerve conduction velocity predict foot problems in diabetic subjects over a 6-year outcome period? Diabetes Care 2002;25:2010-5.

27. Gibbons CH, Freeman R, Tecilazich F, Dinh T, Lyons TE, Gnardellis $\mathrm{C}$, et al. The evolving natural history of neurophysiologic function in patients with well-controlled diabetes. J Peripher Nerv Syst 2013;18:153-61.

28. Davis TM, Yeap BB, Davis WA, Bruce DG. Lipid-lowering therapy and peripheral sensory neuropathy in type 2 diabetes: the Fremantle Diabetes Study. Diabetologia 2008;51:562-6.

29. Malik RA, Williamson S, Abbott C, Carrington AL, Iqbal J, Schady W, et al. Effect of angiotensin-converting-enzyme (ACE) inhibitor trandolapril on human diabetic neuropathy: randomised double-blind controlled trial. Lancet 1998 Dec; 352:1978-81.

30. Polydefkis M, Arezzo J, Nash M, Bril V, Shaibani A, Gordon $\mathrm{RJ}$, et al. Safety and efficacy of ranirestat in patients with mildto-moderate diabetic sensorimotor polyneuropathy. J Peripher Nerv Syst 2015;20:363-71.

31. Javed S, Petropoulos IN, Tavakoli M, Malik RA. Clinical and diagnostic features of small fiber damage in diabetic polyneuropathy. Handb Clin Neurol 2014;126:275-90.

32. Lee-Kubli C, Marshall AG, Malik RA, Calcutt NA. The H-reflex as a biomarker for spinal disinhibition in painful diabetic neuropathy. Curr Diab Rep 2018;18:1.

33. Ishikawa K, Ott K, Porter RW, Stuart D. Low frequency depression of the $\mathrm{H}$ wave in normal and spinal man. Exp Neurol 1966;15:140-56.

34. Kakinohana O, Hefferan MP, Nakamura S, Kakinohana M, Galik J, Tomori Z, et al. Development of GABA-sensitive spasticity and rigidity in rats after transient spinal cord ischemia: a qualitative and quantitative electrophysiological and histopathological study. Neuroscience 2006;141:1569-83.

35. Jolivalt CG, Lee CA, Ramos KM, Calcutt NA. Allodynia and hyperalgesia in diabetic rats are mediated by GABA and depletion of spinal potassium-chloride co-transporters. Pain 2008;140:48-57.

36. Lee-Kubli CA, Calcutt NA. Altered rate-dependent depression of the spinal H-reflex as an indicator of spinal disinhibition in models of neuropathic pain. Pain 2014;155:250-60.

37. Marshall AG, Lee-Kubli C, Azmi S, Zhang M, Ferdousi M, 
Mixcoatl-Zecuatl T, et al. Spinal disinhibition in experimental and clinical painful diabetic neuropathy. Diabetes 2017;66: 1380-90.

38. Serra J. Microneurography: towards a biomarker of spontaneous pain. Pain 2012;153:1989-90.

39. Kleggetveit IP, Namer B, Schmidt R, Helas T, Ruckel M, Orstavik K, et al. High spontaneous activity of C-nociceptors in painful polyneuropathy. Pain 2012;153:2040-7.

40. Ochoa JL, Campero M, Serra J, Bostock H. Hyperexcitable polymodal and insensitive nociceptors in painful human neuropathy. Muscle Nerve 2005;32:459-72.

41. Serra J. Microneurography: an opportunity for translational drug development in neuropathic pain. Neurosci Lett 2010; 470:155-7.

42. Serra J, Duan WR, Locke C, Sola R, Liu W, Nothaft W. Effects of a T-type calcium channel blocker, ABT-639, on spontaneous activity in C-nociceptors in patients with painful diabetic neuropathy: a randomized controlled trial. Pain 2015;156:2175-83.

43. Dyck PJ, Dyck PJ, Larson TS, O’Brien PC, Velosa JA. Patterns of quantitative sensation testing of hypoesthesia and hyperalgesia are predictive of diabetic polyneuropathy: a study of three cohorts. Nerve growth factor study group. Diabetes Care 2000;23:510-7.

44. Backonja MM, Attal N, Baron R, Bouhassira D, Drangholt M, Dyck PJ, et al. Value of quantitative sensory testing in neurological and pain disorders: NeuPSIG consensus. Pain 2013; 154:1807-19.

45. Bird SJ, Brown MJ, Spino C, Watling S, Foyt HL. Value of repeated measures of nerve conduction and quantitative sensory testing in a diabetic neuropathy trial. Muscle Nerve 2006; 34:214-24.

46. Gelber DA, Pfeifer MA, Broadstone VL, Munster EW, Peterson M, Arezzo JC, et al. Components of variance for vibratory and thermal threshold testing in normal and diabetic subjects. J Diabetes Complications 1995;9:170-6.

47. Shy ME, Frohman EM, So YT, Arezzo JC, Cornblath DR, Giuliani MJ, et al. Quantitative sensory testing: report of the Therapeutics and Technology Assessment Subcommittee of the American Academy of Neurology. Neurology 2003;60:898904.

48. Devigili G, Tugnoli V, Penza P, Camozzi F, Lombardi R, Melli $\mathrm{G}$, et al. The diagnostic criteria for small fibre neuropathy: from symptoms to neuropathology. Brain 2008;131(Pt 7): 1912-25.

49. Wahren J, Foyt H, Daniels M, Arezzo JC. Long-acting C-pep- tide and neuropathy in type 1 diabetes: a 12-month clinical trial. Diabetes Care 2016;39:596-602.

50. Melzack R. The short-form McGill Pain Questionnaire. Pain 1987;30:191-7.

51. Zelman DC, Gore M, Dukes E, Tai KS, Brandenburg N. Validation of a modified version of the Brief Pain Inventory for painful diabetic peripheral neuropathy. J Vasc Nurs 2005;23: 97-104.

52. Bouhassira D, Attal N, Fermanian J, Alchaar H, Gautron M, Masquelier E, et al. Development and validation of the Neuropathic Pain Symptom Inventory. Pain 2004;108:248-57.

53. Feldman EL, Stevens MJ, Thomas PK, Brown MB, Canal N, Greene DA. A practical two-step quantitative clinical and electrophysiological assessment for the diagnosis and staging of diabetic neuropathy. Diabetes Care 1994;17:1281-9.

54. Abraham A, Barnett C, Katzberg HD, Lovblom LE, Perkins BA, Bril V. Toronto Clinical Neuropathy Score is valid for a wide spectrum of polyneuropathies. Eur J Neurol 2018;25: 484-90.

55. Powell HC, Rosoff J, Myers RR. Microangiopathy in human diabetic neuropathy. Acta Neuropathol 1985;68:295-305.

56. Kalichman MW, Powell HC, Mizisin AP. Reactive, degenerative, and proliferative Schwann cell responses in experimental galactose and human diabetic neuropathy. Acta Neuropathol 1998;95:47-56.

57. Llewelyn JG, Gilbey SG, Thomas PK, King RH, Muddle JR, Watkins PJ. Sural nerve morphometry in diabetic autonomic and painful sensory neuropathy. A clinicopathological study. Brain 1991;114(Pt 2):867-92.

58. Mizisin AP, Nelson RW, Sturges BK, Vernau KM, Lecouteur RA, Williams DC, et al. Comparable myelinated nerve pathology in feline and human diabetes mellitus. Acta Neuropathol 2007;113:431-42.

59. Sima AA, Bril V, Nathaniel V, McEwen TA, Brown MB, Lattimer SA, et al. Regeneration and repair of myelinated fibers in sural-nerve biopsy specimens from patients with diabetic neuropathy treated with sorbinil. N Engl J Med 1988;319:54855.

60. Sima AA, Greene DA, Brown MB, Hohman TC, Hicks D, Graepel GJ, et al. Effect of hyperglycemia and the aldose reductase inhibitor tolrestat on sural nerve biochemistry and morphometry in advanced diabetic peripheral polyneuropathy. The Tolrestat Study Group. J Diabetes Complications 1993;7:157-69.

61. Breiner A, Lovblom LE, Perkins BA, Bril V. Does the prevail- 
ing hypothesis that small-fiber dysfunction precedes large-fiber dysfunction apply to type 1 diabetic patients? Diabetes Care 2014;37:1418-24.

62. Lauria G, Bakkers M, Schmitz C, Lombardi R, Penza P, Devigili $\mathrm{G}$, et al. Intraepidermal nerve fiber density at the distal leg: a worldwide normative reference study. J Peripher Nerv Syst 2010;15:202-7.

63. Pittenger GL, Mehrabyan A, Simmons K, Amandarice, Dublin C, Barlow P, et al. Small fiber neuropathy is associated with the metabolic syndrome. Metab Syndr Relat Disord 2005;3: 113-21.

64. Azmi S, Jeziorska M, Ferdousi M, Petropoulos IN, Ponirakis G, Marshall A, et al. Early nerve fibre regeneration in individuals with type 1 diabetes after simultaneous pancreas and kidney transplantation. Diabetologia 2019;62:1478-87.

65. Joint Task Force of the EFNS and the PNS. European Federation of Neurological Societies/Peripheral Nerve Society guideline on the use of skin biopsy in the diagnosis of small fiber neuropathy. Report of a joint task force of the European Federation of Neurological Societies and the Peripheral Nerve Society. J Peripher Nerv Syst 2010;15:79-92.

66. Doss AL, Smith PG. Nerve-Langerhans cell interactions in diabetes and aging. Histol Histopathol 2012;27:1589-98.

67. Collongues N, Samama B, Schmidt-Mutter C, Chamard-Witkowski L, Debouverie M, Chanson JB, et al. Quantitative and qualitative normative dataset for intraepidermal nerve fibers using skin biopsy. PLoS One 2018;13:e0191614.

68. Cheng HT, Dauch JR, Porzio MT, Yanik BM, Hsieh W, Smith AG, et al. Increased axonal regeneration and swellings in intraepidermal nerve fibers characterize painful phenotypes of diabetic neuropathy. J Pain 2013;14:941-7.

69. Cheung A, Podgorny P, Martinez JA, Chan C, Toth C. Epider$\mathrm{mal}$ axonal swellings in painful and painless diabetic peripheral neuropathy. Muscle Nerve 2015;51:505-13.

70. Lauria G, Morbin M, Lombardi R, Borgna M, Mazzoleni G, Sghirlanzoni A, et al. Axonal swellings predict the degeneration of epidermal nerve fibers in painful neuropathies. Neurology 2003;61:631-6.

71. Khoshnoodi M, Truelove S, Polydefkis M. Effect of diabetes type on long-term outcome of epidermal axon regeneration. Ann Clin Transl Neurol 2019;6:2088-96.

72. Wang N, Gibbons $\mathrm{CH}$. Skin biopsies in the assessment of the autonomic nervous system. Handb Clin Neurol 2013;117:3718.

73. Smith AG, Ramachandran P, Tripp S, Singleton JR. Epidermal nerve innervation in impaired glucose tolerance and diabetesassociated neuropathy. Neurology 2001;57:1701-4.

74. Kluding PM, Pasnoor M, Singh R, Jernigan S, Farmer K, Rucker J, et al. The effect of exercise on neuropathic symptoms, nerve function, and cutaneous innervation in people with diabetic peripheral neuropathy. J Diabetes Complications 2012;26:424-9.

75. Singleton JR, Marcus RL, Jackson JE, Lessard MK, Graham TE, Smith AG. Exercise increases cutaneous nerve density in diabetic patients without neuropathy. Ann Clin Transl Neurol 2014;1:844-9.

76. Smith AG, Russell J, Feldman EL, Goldstein J, Peltier A, Smith $\mathrm{S}$, et al. Lifestyle intervention for pre-diabetic neuropathy. Diabetes Care 2006;29:1294-9.

77. Perkins BA, Lovblom LE, Bril V, Scarr D, Ostrovski I, Orszag A, et al. Corneal confocal microscopy for identification of diabetic sensorimotor polyneuropathy: a pooled multinational consortium study. Diabetologia 2018;61:1856-61.

78. Dabbah MA, Graham J, Petropoulos IN, Tavakoli M, Malik RA. Automatic analysis of diabetic peripheral neuropathy using multi-scale quantitative morphology of nerve fibres in corneal confocal microscopy imaging. Med Image Anal 2011; 15:738-47.

79. Williams BM, Borroni D, Liu R, Zhao Y, Zhang J, Lim J, et al. An artificial intelligence-based deep learning algorithm for the diagnosis of diabetic neuropathy using corneal confocal microscopy: a development and validation study. Diabetologia 2020;63:419-30.

80. Malik RA, Kallinikos P, Abbott CA, van Schie CH, Morgan P, Efron N, et al. Corneal confocal microscopy: a non-invasive surrogate of nerve fibre damage and repair in diabetic patients. Diabetologia 2003;46:683-8.

81. Petropoulos IN, Alam U, Fadavi H, Marshall A, Asghar O, Dabbah MA, et al. Rapid automated diagnosis of diabetic peripheral neuropathy with in vivo corneal confocal microscopy. Invest Ophthalmol Vis Sci 2014;55:2071-8.

82. Petropoulos IN, Manzoor T, Morgan P, Fadavi H, Asghar O, Alam U, et al. Repeatability of in vivo corneal confocal microscopy to quantify corneal nerve morphology. Cornea 2013; 32:e83-9.

83. Chen X, Graham J, Dabbah MA, Petropoulos IN, Ponirakis G, Asghar $\mathrm{O}$, et al. Small nerve fiber quantification in the diagnosis of diabetic sensorimotor polyneuropathy: comparing corneal confocal microscopy with intraepidermal nerve fiber density. Diabetes Care 2015;38:1138-44. 
84. Dehghani C, Pritchard N, Edwards K, Russell AW, Malik RA, Efron N. Risk factors associated with corneal nerve alteration in type 1 diabetes in the absence of neuropathy: a longitudinal in vivo corneal confocal microscopy study. Cornea 2016;35: $847-52$.

85. Jia X, Wang X, Wang X, Pan Q, Xian T, Yu X, et al. In vivo corneal confocal microscopy detects improvement of corneal nerve parameters following glycemic control in patients with type 2 diabetes. J Diabetes Res 2018;2018:8516276.

86. Jolivalt CG, Frizzi KE, Guernsey L, Marquez A, Ochoa J, Rodriguez $\mathrm{M}$, et al. Peripheral neuropathy in mouse models of diabetes. Curr Protoc Mouse Biol 2016;6:223-55.

87. Gardiner NJ, Freeman OJ. Can diabetic neuropathy be modeled in vitro? Int Rev Neurobiol 2016;127:53-87.

88. Goncalves NP, Vaegter CB, Andersen H, Ostergaard L, Calcutt NA, Jensen TS. Schwann cell interactions with axons and microvessels in diabetic neuropathy. Nat Rev Neurol 2017;13: $135-47$.

89. Hadimani MB, Purohit MK, Vanampally C, Van der Ploeg R, Arballo V, Morrow D, et al. Guaifenesin derivatives promote neurite outgrowth and protect diabetic mice from neuropathy. J Med Chem 2013;56:5071-8.

90. Habash T, Saleh A, Roy Chowdhury SK, Smith DR, Fernyhough $\mathrm{P}$. The proinflammatory cytokine, interleukin-17A, augments mitochondrial function and neurite outgrowth of cultured adult sensory neurons derived from normal and diabetic rats. Exp Neurol 2015;273:177-89.

91. Takaku S, Yako H, Niimi N, Akamine T, Kawanami D, Utsunomiya $\mathrm{K}$, et al. Establishment of a myelinating co-culture system with a motor neuron-like cell line NSC-34 and an adult rat Schwann cell line IFRS1. Histochem Cell Biol 2018; 149:537-43.

92. Urban MJ, Li C, Yu C, Lu Y, Krise JM, McIntosh MP, et al. Inhibiting heat-shock protein 90 reverses sensory hypoalgesia in diabetic mice. ASN Neuro 2010;2:e00040.

93. Biessels GJ, Bril V, Calcutt NA, Cameron NE, Cotter MA, Dobrowsky R, et al. Phenotyping animal models of diabetic neuropathy: a consensus statement of the diabetic neuropathy study group of the EASD (Neurodiab). J Peripher Nerv Syst 2014;19:77-87.

94. Beiswenger KK, Calcutt NA, Mizisin AP. Epidermal nerve fiber quantification in the assessment of diabetic neuropathy. Acta Histochem 2008;110:351-62.

95. Chen DK, Frizzi KE, Guernsey LS, Ladt K, Mizisin AP, Calcutt NA. Repeated monitoring of corneal nerves by confocal mi- croscopy as an index of peripheral neuropathy in type-1 diabetic rodents and the effects of topical insulin. J Peripher Nerv Syst 2013;18:306-15.

96. Jakobsen J. Axonal dwindling in early experimental diabetes. II. A study of isolated nerve fibres. Diabetologia 1976;12:54753.

97. Jakobsen J. Axonal dwindling in early experimental diabetes. I. A study of cross sectioned nerves. Diabetologia 1976;12:53946.

98. Jakobsen J, Sidenius P, Gundersen HJ, Osterby R. Quantitative changes of cerebral neocortical structure in insulin-treated long-term streptozocin-induced diabetes in rats. Diabetes 1987;36:597-601.

99. Sidenius P, Jakobsen J. Reduced perikaryal volume of lower motor and primary sensory neurons in early experimental diabetes. Diabetes 1980;29:182-6.

100. Thomas PK, Fraher JP, O’Leary D, Moran MA, Cole M, King $\mathrm{RH}$. Relative growth and maturation of axon size and myelin thickness in the tibial nerve of the rat. 2. Effect of streptozotocin-induced diabetes. Acta Neuropathol 1990;79:375-86.

101. Anderson NJ, King MR, Delbruck L, Jolivalt CG. Role of insulin signaling impairment, adiponectin and dyslipidemia in peripheral and central neuropathy in mice. Dis Model Mech 2014;7:625-33.

102. Sima AA. Encephalopathies: the emerging diabetic complications. Acta Diabetol 2010;47:279-93.

103. Biessels GJ, Nobili F, Teunissen CE, Simo R, Scheltens P. Understanding multifactorial brain changes in type 2 diabetes: a biomarker perspective. Lancet Neurol 2020;19:699-710.

104. Kennedy JM, Zochodne DW. Experimental diabetic neuropathy with spontaneous recovery: is there irreparable damage? Diabetes 2005;54:830-7.

105. Mattingly GE, Fischer VW. Peripheral neuropathy following prolonged exposure to streptozotocin-induced diabetes in rats: a teased nerve fiber study. Acta Neuropathol 1983;59: 133-8.

106. Powell HC, Myers RR. Axonopathy and microangiopathy in chronic alloxan diabetes. Acta Neuropathol 1984;65:128-37.

107. Robertson DM, Sima AA. Diabetic neuropathy in the mutant mouse [C57BL/ks(db/db)]: a morphometric study. Diabetes 1980;29:60-7.

108. Wada R, Koyama M, Mizukami H, Odaka H, Ikeda H, Yagihashi S. Effects of long-term treatment with alpha-glucosidase inhibitor on the peripheral nerve function and structure in Goto-Kakizaki rats: a genetic model for type 2 diabetes. Dia- 
betes Metab Res Rev 1999;15:332-7.

109. Yagihashi S, Nishihira M, Baba M. Morphometrical analysis of the peripheral nerve lesions in experimental diabetes rats. Tohoku J Exp Med 1979;129:139-49.

110. Gregory JA, Jolivalt CG, Goor J, Mizisin AP, Calcutt NA. Hypertension-induced peripheral neuropathy and the combined effects of hypertension and diabetes on nerve structure and function in rats. Acta Neuropathol 2012;124:561-73.

111. Forrest KY, Maser RE, Pambianco G, Becker DJ, Orchard TJ. Hypertension as a risk factor for diabetic neuropathy: a prospective study. Diabetes 1997;46:665-70.

112. Romanovsky D, Hastings SL, Stimers JR, Dobretsov M. Relevance of hyperglycemia to early mechanical hyperalgesia in streptozotocin-induced diabetes. J Peripher Nerv Syst 2004;9: 62-9.

113. Romanovsky D, Cruz NF, Dienel GA, Dobretsov M. Mechanical hyperalgesia correlates with insulin deficiency in normoglycemic streptozotocin-treated rats. Neurobiol Dis 2006;24: 384-94.

114. Romanovsky D, Dobretsov M. Pressure-induced pain: early sign of diabetes-associated impairment of insulin production in rats. Neurosci Lett 2010;483:110-3.

115. Pabbidi RM, Cao DS, Parihar A, Pauza ME, Premkumar LS. Direct role of streptozotocin in inducing thermal hyperalgesia by enhanced expression of transient receptor potential vanilloid 1 in sensory neurons. Mol Pharmacol 2008;73:995-1004.

116. Andersson DA, Filipovic MR, Gentry C, Eberhardt M, Vastani N, Leffler A, et al. Streptozotocin stimulates the ion channel TRPA1 directly: involvement of peroxynitrite. J Biol Chem 2015;290:15185-96.

117. Karunanayake EH, Hearse DJ, Mellows G. The synthesis of [14C] streptozotocin and its distribution and excretion in the rat. Biochem J 1974;142:673-83.

118. Davidson E, Coppey L, Lu B, Arballo V, Calcutt NA, Gerard C, et al. The roles of streptozotocin neurotoxicity and neutral endopeptidase in murine experimental diabetic neuropathy. Exp Diabetes Res 2009;2009:431980.

119. Yorek MA. Alternatives to the streptozotocin-diabetic rodent. Int Rev Neurobiol 2016;127:89-112.

120. Walker D, Carrington A, Cannan SA, Sawicki D, Sredy J, Boulton AJ, et al. Structural abnormalities do not explain the early functional abnormalities in the peripheral nerves of the streptozotocin diabetic rat. J Anat 1999;195(Pt 3):419-27.

121. Tomlinson DR, Moriarty RJ, Mayer JH. Prevention and reversal of defective axonal transport and motor nerve conduction velocity in rats with experimental diabetes by treatment with the aldose reductase inhibitor sorbinil. Diabetes 1984;33:4706.

122. Oates PJ. Aldose reductase, still a compelling target for diabetic neuropathy. Curr Drug Targets 2008;9:14-36.

123. Coderre TJ, Laferriere A. The emergence of animal models of chronic pain and logistical and methodological issues concerning their use. J Neural Transm (Vienna) 2020;127:393406.

124. Le Bars D, Gozariu M, Cadden SW. Animal models of nociception. Pharmacol Rev 2001;53:597-652.

125. Lee-Kubli CA, Calcutt NA. Painful neuropathy: mechanisms. Handb Clin Neurol 2014;126:533-57.

126. Calcutt NA, Malmberg AB, Yamamoto T, Yaksh TL. Tolrestat treatment prevents modification of the formalin test model of prolonged pain in hyperglycemic rats. Pain 1994;58:413-20.

127. Ohsawa M, Kashiwazaki T, Kamei J. Modulation of the formalin-induced nociceptive response by diabetes: possible involvement of protein kinase C. Brain Res 1998;803:198-203.

128. Calcutt NA. Modeling diabetic sensory neuropathy in rats. Methods Mol Med 2004;99:55-65.

129. Themistocleous AC, Ramirez JD, Shillo PR, Lees JG, Selvarajah D, Orengo C, et al. The Pain in Neuropathy Study (PiNS): a cross-sectional observational study determining the somatosensory phenotype of painful and painless diabetic neuropathy. Pain 2016;157:1132-45.

130. Jourdan D, Ardid D, Eschalier A. Analysis of ultrasonic vocalisation does not allow chronic pain to be evaluated in rats. Pain 2002;95:165-73.

131. Chen X, Levine JD. Hyper-responsivity in a subset of C-fiber nociceptors in a model of painful diabetic neuropathy in the rat. Neuroscience 2001;102:185-92.

132. Khan GM, Chen SR, Pan HL. Role of primary afferent nerves in allodynia caused by diabetic neuropathy in rats. Neuroscience 2002;114:291-9.

133. Schuelert N, Gorodetskaya N, Just S, Doods H, Corradini L. Electrophysiological characterization of spinal neurons in different models of diabetes type 1- and type 2-induced neuropathy in rats. Neuroscience 2015;291:146-54.

134. Chen SR, Pan HL. Hypersensitivity of spinothalamic tract neurons associated with diabetic neuropathic pain in rats. J Neurophysiol 2002;87:2726-33.

135. Tan AM, Samad OA, Fischer TZ, Zhao P, Persson AK, Waxman SG. Maladaptive dendritic spine remodeling contributes to diabetic neuropathic pain. J Neurosci 2012;32:6795-807. 
136. Pertovaara A, Wei H, Kalmari J, Ruotsalainen M. Pain behavior and response properties of spinal dorsal horn neurons following experimental diabetic neuropathy in the rat: modulation by nitecapone, a COMT inhibitor with antioxidant properties. Exp Neurol 2001;167:425-34.

137. Calcutt NA, Stiller C, Gustafsson H, Malmberg AB. Elevated substance-P-like immunoreactivity levels in spinal dialysates during the formalin test in normal and diabetic rats. Brain Res 2000;856:20-7.

138. Malmberg AB, O'Connor WT, Glennon JC, Cesena R, Calcutt NA. Impaired formalin-evoked changes of spinal amino acid levels in diabetic rats. Brain Res 2006;1115:48-53.

139. Wei H, Viisanen H, Amorim D, Koivisto A, Pertovaara A. Dissociated modulation of conditioned place-preference and mechanical hypersensitivity by a TRPA1 channel antagonist in peripheral neuropathy. Pharmacol Biochem Behav 2013;104: 90-6.

140. Wagner K, Lee KS, Yang J, Hammock BD. Epoxy fatty acids mediate analgesia in murine diabetic neuropathy. Eur J Pain 2017;21:456-65.

141. Wagner K, Yang J, Inceoglu B, Hammock BD. Soluble epoxide hydrolase inhibition is antinociceptive in a mouse model of diabetic neuropathy. J Pain 2014;15:907-14.

142. Agarwal N, Helmstadter J, Rojas DR, Bali KK, Gangadharan V, Kuner R. Evoked hypoalgesia is accompanied by tonic pain and immune cell infiltration in the dorsal root ganglia at late stages of diabetic neuropathy in mice. Mol Pain 2018;14:17448-
06918817975.

143. Davidson EP, Coppey LJ, Holmes A, Yorek MA. Changes in corneal innervation and sensitivity and acetylcholine-mediated vascular relaxation of the posterior ciliary artery in a type 2 diabetic rat. Invest Ophthalmol Vis Sci 2012;53:1182-7.

144. Beiswenger KK, Calcutt NA, Mizisin AP. Dissociation of thermal hypoalgesia and epidermal denervation in streptozotocin-diabetic mice. Neurosci Lett 2008;442:267-72.

145. Calcutt NA, Chen P, Hua XY. Effects of diabetes on tissue content and evoked release of calcitonin gene-related peptide-like immunoreactivity from rat sensory nerves. Neurosci Lett 1998;254:129-32.

146. Tomlinson DR, Fernyhough P, Diemel LT. Neurotrophins and peripheral neuropathy. Philos Trans R Soc Lond B Biol Sci 1996;351:455-62.

147. Fernyhough P, Calcutt NA. New directions in diabetic neuropathy: evolution or extinction? Int Rev Neurobiol 2016;127:22934.

148. Davidson EP, Coppey LJ, Shevalye H, Obrosov A, Kardon RH, Yorek MA. Impaired corneal sensation and nerve loss in a type 2 rat model of chronic diabetes is reversible with combination therapy of menhaden oil, a-lipoic acid, and enalapril. Cornea 2017;36:725-31.

149. Calcutt NA, Smith DR, Frizzi K, Sabbir MG, Chowdhury SK, Mixcoatl-Zecuatl T, et al. Selective antagonism of muscarinic receptors is neuroprotective in peripheral neuropathy. J Clin Invest 2017;127:608-22. 